\title{
The consequences of different strategies for measuring tax evasion behavior
}

\author{
Ghavam Ahmadi $^{\mathrm{a}^{*}}$, Ali Bayat ${ }^{\mathrm{b}}$ and Homa Doroudi ${ }^{\mathrm{b}}$
}

${ }^{a}$ Masters Student, Department of Management and Accounting, Zanjan Branch, Islamic Azad University, Zanjan, Iran ${ }^{b}$ Assistant Professor, Department of Management and Accounting, Zanjan Branch, Islamic Azad University, Zanjan, Iran

\section{H R O N I C L E}

\section{Article history:}

Received June 4, 2014

Accepted 12 October 2014

Available online

October 202014

Tax evasion

Tax strategy

Zanjan

\section{A B S T R A C T}

This paper presents a study to investigate the effect of tax strategy on tax evasion in province of Zanjan, Iran. The study selects two randomly selected populations of 100 people from Tax organization and the people who file income tax with revenue agency. The study designs a questionnaire in Likert scale to study the effects of five variables namely; promote tax culture, lack of belief in tax payment consequences, filing false tax statement, tax exemption and general culture community as independent variables on tax evasion behavior. Using regression technique, the study has determined positive and meaningful relationships between tax evasion and independent variables.

\section{Introduction}

Tax is the primary source of development of economy and reaching sustainable development. However, a critical review of existing measures of tax evasion implies the necessity for innovative measurement tax strategies (Korndörfer et al., 2014). Elffers et al. (1987) developed a new method for documenting cases of individual tax evasion without compromising confidentiality. According to Skinner and Slemrod (1985), public policy towards tax evasion reflects complex and competing objectives of gathering taxes effectively and treating taxpayers fairly. Janeba and Peters (1999) applied a game-theoretic approach to analyze the taxation of interest income in Europe in the presence of tax evasion. The model helps assess the success of different reform proposals. They argued that the tax treatment of nonresidents' interest income plays essential role. Marrelli and Martina (1988) analyzed the optimal tax evasion decision in the context of an oligopolistic market with quantity setting companies. They reported that the optimal amount of tax evasion for each firm could not only depend on the degree of collusion in the market but also on the relative market shares of the companies; increasing collusion, however, leads to a larger amount of tax evasion in the market.

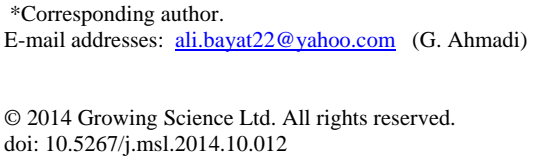


Crocker and Slemrod (2005) investigated corporate tax evasion in the context of the contractual relationship between the shareholders of a company and a tax manager who possesses private information regarding the extent of legally permissible reductions in taxable income, and who may also undertake illegal tax evasion. David and Semerád (2014) dealt with the possibilities of estimating the amount of tax evasion concerning value added tax in the fuel market in the Czech Republic. They proposed a specific original method of quantification of tax evasion on the basis of data associated with distributor prices, gathered during the year 2012, and information obtained from the survey of interested entities.

Bertotti and Modanese (2014) investigated the impact of tax evasion on the income distribution and the inequality index of a society through a kinetic model explained by a set of nonlinear ordinary differential equations. The model helps compute the global outcome of binary and multiple microscopic interactions between individuals. When evasion happens, both individuals involved in a binary interaction take advantage of it, while the rest of the society is deprived of a part of the planned redistribution. The impact of evasion on the income distribution was to decrease the population of the middle classes and it could increase the poor and rich classes. They studied the dependence of the Gini index on various parameters when the evasion rate increases proportionally to a taxation rate. They also evaluated the relative probability of class advancement of individuals because of direct interactions and welfare provisions, and some typical temporal rates of convergence of the income distribution to its equilibrium state.

\section{The proposed study}

This paper presents a study to investigate the effect of tax strategy on tax evasion in province of Zanjan, Iran. There are approximately 250 employees who work for Tax organization and 10000 residence normally file income tax with the revenue agency in city of Zanjan, Iran. The study selects two randomly selected populations of 100 people from Tax organization and the people who file income tax with revenue agency. In our survey, 300 of the people who participated in our survey were male and the remaining 100 people were female. In addition, 303 of them were married and 97 of them were single. Fig. 1 demonstrates other characteristics of the participants.

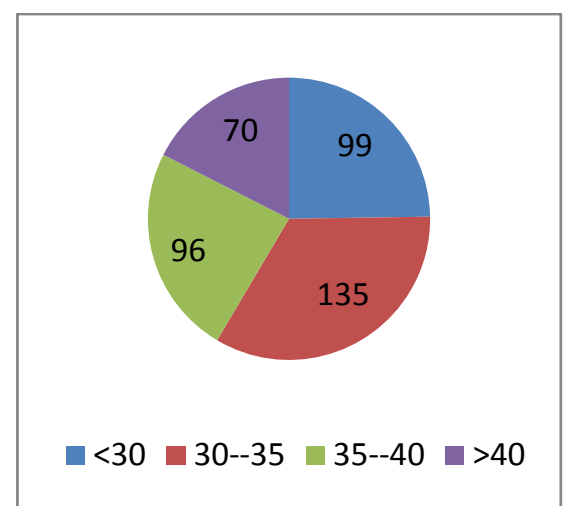

Age

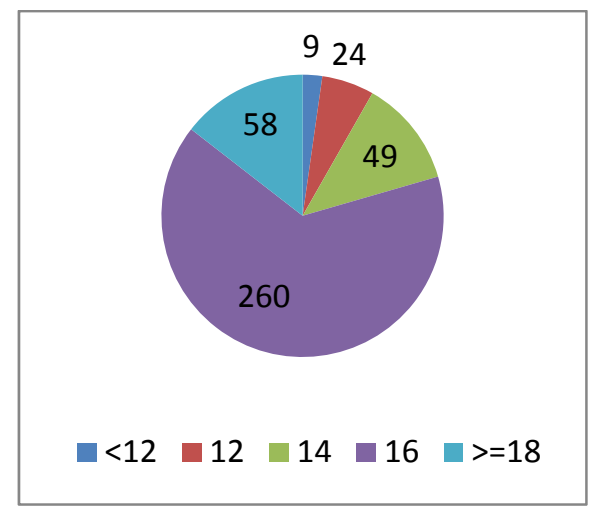

Years of education

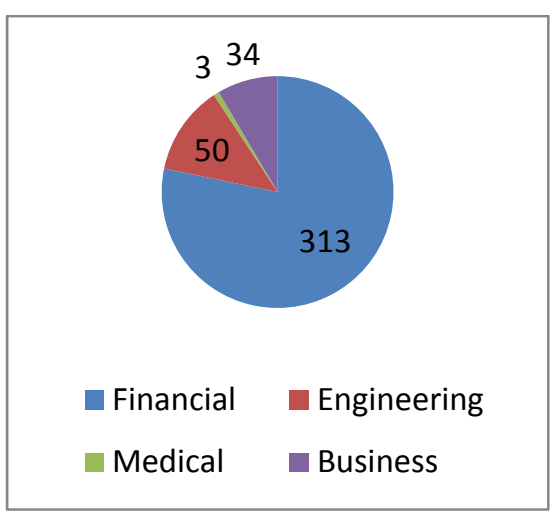

Area of business activities

Fig. 1. Personal characteristics of the participants

As we can observe from the results of Fig. 1, most participants were middle-aged people with some university degrees and they were involved mainly in administration as well as financial activities. The proposed study of this paper uses regression technique to study the relationship between tax evasion as dependent variable and five independent variables, which is stated as follows,

$y=\beta_{0}+\beta_{1} x_{1}+\beta_{2} x_{2}+\beta_{3} x_{3}+\beta_{4}+\beta_{5} x_{5}+\varepsilon$, 
where $x_{1}$ to $x_{5}$ represent failure to effectively promote tax culture, lack of belief in tax payment consequences, filing false tax statement, tax exemption and general culture community, respectively. In addition, $\beta_{0}$ to $\beta_{5}$ represent the coefficients to be estimated and finally, $\varepsilon$ represents the residuals. The proposed study of this paper designs a questionnaire in Likert scale and first distributes it among 20 experts, 10 from each group, to verify the questionnaire. Table 1 demonstrates Cronbach alpha for all components of the survey.

Table 1

The summary of Cronbach alphas

\begin{tabular}{lc}
\hline Variable & Cronbach alpha \\
\hline Tax evasion & 0.732 \\
Failure to effectively promote tax culture & 0.814 \\
Lack of belief in tax payment consequences & 0.788 \\
Filing false tax statement & 0.763 \\
Tax exemption & 0.752 \\
General culture community & 0.753 \\
\hline
\end{tabular}

As we can observe from the results of Table 1, all components of the survey are within desirable level and we may process other components of the survey. Fig. 1 demonstrates the results of changes in residuals associated with dependent variable, tax evasion.

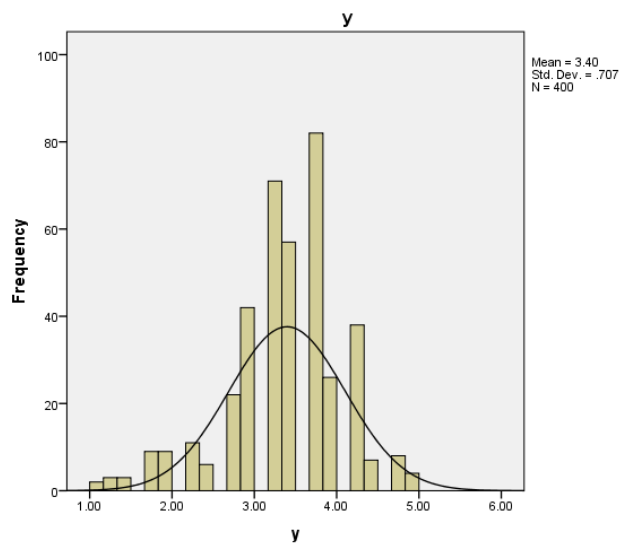

Fig. 1. Distribution of residuals of tax evasion

As we can observe from the result of Fig. 1, the residuals seem to be normally distributed. In addition, Kolmogorov-Smirnov test has been executed on different variables and Table 2 shows the results of our survey.

Table 2

The summary of Kolmogorov-Smirnov method

\begin{tabular}{lcccccc}
\hline & $\mathrm{y}$ & $\mathrm{x}_{1}$ & $\mathrm{x}_{2}$ & $\mathrm{x}_{3}$ & $\mathrm{x}_{4}$ & $\mathrm{x}_{5}$ \\
\hline Mean & 3.3971 & 3.1271 & 3.3687 & 3.222 & 3.4579 & 3.371 \\
Standard deviation & 0.70733 & 0.71894 & 0.61346 & 0.7629 & 0.72032 & 0.6902 \\
Kolmogorov-Smirnov Z & 0.125 & 0.063 & 0.062 & 0.071 & 0.077 & 0.071 \\
Sig. & $.000^{\mathrm{C}}$ & $.001^{\mathrm{C}}$ & $.001^{\mathrm{C}}$ & $.000^{\mathrm{C}}$ & $.000^{\mathrm{C}}$ & $.000^{\mathrm{C}}$ \\
\hline
\end{tabular}

c Sig. $<0.01$

The results of Table 2 clearly indicate that all components of the survey were normally distributed when the level of significance is one percent.

\section{The results}

In this section, we present the results of the implementation of regression technique on Eq. (1). Table 3 shows details of our findings. In addition, Table 4 demonstrates the results of ANOVA test. 
Table 3

The summary of regression technique

\begin{tabular}{|c|c|c|c|c|c|}
\hline \multirow[t]{2}{*}{ Model } & \multicolumn{2}{|c|}{$\begin{array}{l}\text { Unstandardized } \\
\text { Coefficients }\end{array}$} & \multirow{2}{*}{$\begin{array}{c}\text { Standardized } \\
\text { Coefficients } \\
\text { Beta } \\
\end{array}$} & \multirow[t]{2}{*}{$\mathrm{t}$} & \multirow[t]{2}{*}{ Sig. } \\
\hline & $\mathrm{B}$ & Std. Error & & & \\
\hline (Constant) & -0.014 & 0.004 & & -3.168 & 0.002 \\
\hline Promote tax culture & 0.202 & 0.001 & 0.335 & 218.636 & 0 \\
\hline Lack of belief in tax payment consequences & 0.199 & 0.001 & 0.291 & 218.593 & 0 \\
\hline Filing false tax statement & 0.202 & 0.001 & 0.266 & 193.207 & 0 \\
\hline Tax exemption & 0.202 & 0.001 & 0.265 & 199.135 & 0 \\
\hline General culture community & 0.2 & 0.001 & 0.298 & 195.461 & 0 \\
\hline
\end{tabular}

Table 4

The results of ANOVA test

\begin{tabular}{lccccc}
\hline & Sum of Squares & df & Mean Square & F & Sig. \\
\hline Regression & 93.735 & 5 & 18.747 & 582202.28 & $.000^{\mathrm{b}}$ \\
Residual & 0.013 & 394 & 0 & & \\
Total & 93.747 & 399 & & & \\
\hline
\end{tabular}

As we can observe from the results of Table $3 \mathrm{~F}$-value is statistically meaningful. In addition, all tstudent values are also statistically meaningful when the level of significance is one percent.

\section{Discussion and conclusion}

According to the results of Table 3, promoting tax culture is the most important factor influencing on tax evasion behavior. People must understand that tax is the primary source of development of economy. People need to understand that the country's infrastructure development depends on government's income and tax is the primary sources for sustainable development. In our survey, general culture of community is the second important issues influencing on sustainable development. Lack of belief in tax payment consequences is the next factor influencing on tax evasion behavior. In our survey, people may be under the impression that government may always collect necessary budget through selling natural resources such as oil and gas. They may not think the collecting tax is a more diversified method for revenue agency department and reduces the risk of budget deficit. Many people may report unrealistic numbers for their tax and government must use modern techniques to prevent any false statement.

\section{References}

Bertotti, M. L., \& Modanese, G. (2014). Micro to macro models for income distribution in the absence and in the presence of tax evasion. Applied Mathematics and Computation, 244, 836-846.

Crocker, K. J., \& Slemrod, J. (2005). Corporate tax evasion with agency costs. Journal of Public Economics, 89(9), 1593-1610.

David, P., \& Semerád, P. (2014). Possibilities of Measuring Tax Evasion Related to Fuel Sale. Procedia Economics and Finance, 12, 121-129.

Elffers, H., Weigel, R. H., \& Hessing, D. J. (1987). The consequences of different strategies for measuring tax evasion behavior. Journal of Economic Psychology, 8(3), 311-337.

Janeba, E., \& Peters, W. (1999). Tax evasion, tax competition and the gains from nondiscrimination: The case of interest taxation in Europe. The Economic Journal, 109(452), 93-101.

Korndörfer, M., Krumpal, I., \& Schmukle, S. C. (2014). Measuring and explaining tax evasion: Improving self-reports using the crosswise model. Journal of Economic Psychology, 45, 18-32.

Marrelli, M., \& Martina, R. (1988). Tax evasion and strategic behaviour of the firms. Journal of Public Economics, 37(1), 55-69.

Skinner, J., \& Slemrod, J. (1985). An economic perspective on tax evasion. National Tax Journal, 38(3), 345-353. 